The accompanying figures were obtained in this way, and do not include the hundreds and probably thousands of caterpillars which we know were killed at Wallingford by the lead arsenate and the tanglefoot bands; neither do they include those killed by fire in the walls at Stonington, but are simply a record of the insects found and destroyed by the men working day after day.

It should also be stated that the money expended in this work by the state $(\$ 18,681.39)$ includes the cost of much scouting outside the infested regions, following up reports of infestations, and the traveling expenses for most of the work of inspecting imported nursery stock for the last three years. It also includes the cost of scouting and destroying brown-tail nests in five towns in the northeast corner of the state last winter, so that the actual amount expended in gypsy moth extermination would be considerably less. The Federal money has practically all been used for scouting, both in and outside of the infested territory.

(Proceedings to be continued.)

\title{
UNCONSIDERED FACTORS IN DISEASE TRANSMISSION BY BLOOD-SUCKING INSECTS
}

By Frederick KNAB, Bureau of Entomology, Washington, D. C.

The study of the rôle of blood-sucking insects in the transmission of disease is a recent one, and it is still to a large extent vague and chaotic. Its teachings are not only built up largely on hastily collected and faulty data, but they are replete with errors. Many of the investigators not only have lacked the necessary knowledge of biology, but the mastery of detail, along with a broader view, which is eminently necessary in such work. Since the discovery that certain blood-sucking insects are the secondary hosts of pathogenic parasites, nearly every insect that sucks blood, whether habitually or occasionally, has been suspected or considered a possible transmitter of disease. No thought seems to have been given to the conditions, and the characteristics of the individual species of blood-sucking insects, which make disease transmission possible.

In order to be a potential transmitter of human blood-parasites, an insect must be closely associated with man and normally have opportunity to suck his blood repeatedly. It is not sufficient that occasional specimens bite man, as, for example, is the case with forest mosquitoes. Although a person may be bitten by a large number of such mosquitoes, the chances that any of these mosquitoes survive to develop the parasites in question (assuming such development to be possible) and then find opportunity to bite and infect another person are altogether too remote. Applying this criterion, 
not only the majority of mosquitoes, but many other blood-sucking insects, such as Tabanidæ and Simuliidæ, may be confidently eliminated. Moreover these insects are mostly in evidence only during a brief season, so that we have the additional difficulty of a very long interval during which there could be no propagation of the disease in question.

The truth is that all insects that have been found to be transmitters of human blood-disease are more or less closely associated with man and habitually suck his blood. This relation has long been recognized in the case of the two house-mosquitoes of the tropics, the one (Aëdes calopus) being the intermediary host of the yellow fever organism, the other (Culex quinquefasciatus) of those of filariasis and dengue fever, but its significance has not been grasped. It is only through a combination of circumstances that these insects are effective transmitters. These conditions are: The association with man and a predilection for his blood, abundance, comparative longevity $\rightarrow$ which means blood meals repeated at intervals, and practically continuous breeding, so that individuals are always present to act as intermediary hosts of the parasites. When these conditions are fulfilled the chain in the life-cycle of the parasite is continuous and we have an endemic disease. The relations just outlined might be expressed in terms of mathematical formulæ, but nothing would be gained thereby. It is the recognition of the principles involved that is important.

The writer is not at present in a position to review the entire field of disease transmission by biting insects from this viewpoint. However onc more striking example in support of his views may be cited. This is the large hemipter Triatoma (Conorhinus) megistus which Carlos Chagas recently has shown to be the transmitter of a dangerous trypanosome disease of man in Brazil. As I have already pointed out in another place (Proc. Ent. Soc. Wash., xiii, 71, 1911) Triatoma megistus is remarkable among the American members of the genus in showing close adaptation to man. It lives in houses and does not occur naturally apart from man. The eggs are laid in the crevices of walls inside of houses and the young bugs feed on human blood from the start. In spite of its very large size, the bite of the adult accasions so little pain that it does not awaken a sound sleeper. This is clearly adaptational, as the wild species of the genus are known to have a very painful bite. Still another example are the biting flies of the genus Flebotomus, which, in the Mediterranean region transmit the so-called pappataci fever. Here too the species involved are closely associated with man.

It would seem at first thought that Anopheles, in the transmission of malaria, does not fulfill the conditions above formulated. The 
species of Anopheles have not been looked upon as particularly associated with man. However this is only due to the fact that the habits of the Anopheles have not been properly understood and particularly to the failure to differentiate the habits of the different species. There is every indication that those species which transmit malaria thrive in the vicinity of man, while, on the other hand, those species which live apart from man and do not habitually seek his blood are inoffensive. That the habits of the different species of Anopheles differ widely and are in direct relation to their effectiveness as transmitters of malaria is brought out in an interesting manner in the paper by Mr. Jennings on mosquito control in the Panama Canal Zone (printed on the preceding pages of this number). Conversation with him has added further data that support this view. Investigation of the role of the different species in the transmission of malaria, by inducing them to bite malaria carriers, has shown that Anopheles albimanus, the species which thrives particularly about settlements and is most persistent in entering houses and obtaining blood, is the principal factor in malaria transmission-no less than 70 per cent of this species developing the parasites. ${ }^{1}$ An interesting point, brought out in conversation with $\mathrm{Mr}$. Jennings, is that this species appears to be absent from those parts of the upper Chagres River which are uninhabited. It is highly probable that the reason for the absence of Anopheles albimanus from such localities is that this mosquito not only prefers, but probably needs, human blood. It has been suggested that the absence of albimanus from the upper Chagres was due wholly to the absence of suitable breeding-places. It appears, however, that this objection is not valid. Both Mr. Jennings and Mr. Busck have explored the Chagres for mosquitoes and they assure me that there are abundant opportunities for $A$. albimanus to breed. Neither of them found albimanus and they could hardly have failed to do so had it been present. ${ }^{2}$

The observations of James and Liston on the habits of the Anopheles of India show that the species of that country likewise differ in halits,

\footnotetext{
1 Darling, Samuel T., Studies in relation to malaria, Washington, Govt. Printing Office, 1910 .

s Since writing the above I have come upon a record of observations on Ansphles tarsimaculata, a geographic race of albimanus, by the Rev. James Aiken of Berbice, British Cuiana, which support my contention. I'nder the name Cellia allikies he indicates the relation of this species to man as follows: "It is to be noted that on the Canje creek further up than Baracara I found no Anophelina, the same remark applies to the Berbice River above Mara, and in a collection made by Mr. Beckett at Sandhills none appeared. On a visit to the Supenaam creek I was also unsuccessful in finding this mosquito. All these districts are very sparsely populated, and so far as our observations go they are only to be found near human dwellings." (British Guiana Medical Annual for 1906, Demerara, 1907, p. 66.)
} 
and they speak of "domestic" and "wild" species. "However the significance of the phenomenon seems to have escaped them, as it bas subsequent investigators. There is no doubt in the writer's mind that a critical review of the data will show that the Anopheles responsible for the transmission of malaria in India will be found among the "domestic" species, as the term is applied by the above mentioned authors.

There is a paper by Dr. Adolph Lutz of Brazil, on forest mosquitoes and forest malaria, which apparently contradicts the ideas just expressed with reference to Anopheles and malaria." The probabilities are, however, that Doctor Lutz has misinterpreted the facts. His observations were made in the state of São Paulo, during the construction of a railroad from the coast to the capital. The first part of the route was through the moist and heavily forested slope from the table-land to the coast, and while at work here a large part of the construction gang were afflicted with malaria. Lutz searched for the transmitting Anopheles but could find no breeding-places upon the stcep slopes. Finally he determined that only one species of Anopheles (cruzi) was present in the region, and that this bred abundantly in the water held by epiphytic bromeliads. To this species he attributed the outbreak of malaria. Most probably this Anopheles had nothing to do with the outbreak of malaria among the laborers. It is a well-known fact that in the tropics most persons, although apparently in good health, have latent malaria. When such an individual comes under some physical strain, such as overexertion, exposure, or some form of overindulgence, the disease manifests itself. It seems highly probable that this is the explanation of the outbreak observed by Doctor Lutz. The men already harbored latent malaria when they came into the region and the exertion and exposure incident to the work caused the eruption of the disease.

It must be noted in passing that the character of the disease itself, the duration of the parasites in the human blood, has an important bearing on the insect relation. Thus, in the case of yellow fever and dengue, where the parasites are present in the blood only during a very brief period, the association of the two hosts must be a very intimate one. In the case of malaria, where the parasites are present in the blood for a long time, the relation of the transmitting mosquito may easily be a less intimate one. But even here it must be remembered that the gametes, the sexual elements which are destined to

3James, S. P., and Liston, W. Glen. A Monograph of the Anopheles Mosquitoes of India. Calcutta, 1904 (first edit.).

- Iutz, Adolph, Waldmosquitos urd Waldmalaria. Centralbl. f. Bakteriol., Parasitcnk., u. Infektionskr., Abt. 1, Bd. 33, p. 282-292, 1903. 
continue the cycle of the parasite within the mosquito host, are only present and available to the mosquito at definite intervals, and that after a certain time, if no reinfection occurs, these forms disappear altogether.

In conclusion the writer wishes to point out that he is fully aware of a certain class of blood-parasites and transmitters which apparently do not conform to the principles above laid down. One class are the diseases transmitted by ticks, where the parasites are directly transmitted from the tick host to its offspring, and where, for this reason, the insect remains a potential transmitter for a very long period. Another class are the trypanosomes which apparently thrive in a number of different vertebrate hosts and may be transmitted from cattle or wild animals to man. But the observations on this point are by no means conclusive and it is quite possible, as has been repeatedly suggested, that a number of organisms, different but indistinguishable, are involved. It may prove that a revision of the data, from the present viewpoint, may materially alter our conceptions on the subject.

\section{UTILIZATION OF FUNGOUS PARASITES OF COCCIDE AND ALEURODID $\approx$ IN FLORIDA}

By J. R. WATson, Florida Agricultural Experiment Station

As this station is receiving a number of inquiries concerning the success of the experiments which for several years have been in progress here looking towards the control of our worst citrus pests by means of fungi, it has seemed that perhaps a brief statement on the present status of the subject might not be without interest to readers of the Journal of Economic Entomologr. The more so as there seems to be among entomologists a feeling (perhaps well founded as far as most of the states are concerned) of pessimism concerning the practicability of controlling any insect pest by means of its fungous enemies.

Although fungous enemies are here very efficient in checking the ravages of many other insects, as for instance the larvæ of many lepidoptera, the most attention has been given to the scales and to the whiteflies of citrus, and it is with these that the writer will chiefly deal in this brief notice.

History. The presence of parasitic fungi (the Red Aschersonia) was first noted as checking the work of whitefly in Florida by $\mathrm{H}$. J. Webber in 1893 (Report of Fla. Hort. Soc., and Bull. 13 Div. of Veg. Path. U. S. D. A.). Prof. P. H. Rolfs (Fla. Bull. 41, 1897) first noted the Red-headed Scale Fungus (Spharostilbe coccophila) as being a 